\title{
The approach to individualized prediction of human papillomavirus (HPV) infection persistence/clearance in HIV-1-positive adolescent girls based on dynamics of CD4+ counts, viral load, and HAART
}

Julia Kravchenko ${ }^{1 *}$, Staci Sudenga ${ }^{2}$, Igor Akushevich ${ }^{3}$, Craig M Wilson², Sadeep Shrestha ${ }^{2}$

From $12^{\text {th }}$ International Conference on Malignancies in AIDS and Other Acquired Immunodeficiencies (ICMAOI)

Bethesda, MD, USA. 26-27 April, 2010

\section{Background}

Several studies suggest that $\mathrm{CD} 4^{+} \mathrm{T}$-cell count (CD4) is important in pathogenesis of human papillomavirus (HPV) infection in HIV-positive patients including HPV clearance. CD4 dynamics as well as other co-factors such as highly active antiretroviral therapy (HAART), HIV-1 RNA viral load (VL), demographics, behavioral risks and, clinical diagnosis allows for predicting the absolute probabilities of
HPV clearance/persistence. The modeling approach allows for the utilization of complete datasets and does not require any additional essential assumptions about missing information and possible violations in study design.

\section{Materials and methods}

We analyzed $266 \mathrm{HIV}-1$ positive adolescent girls from the Reaching for Excellence in Adolescent Care and

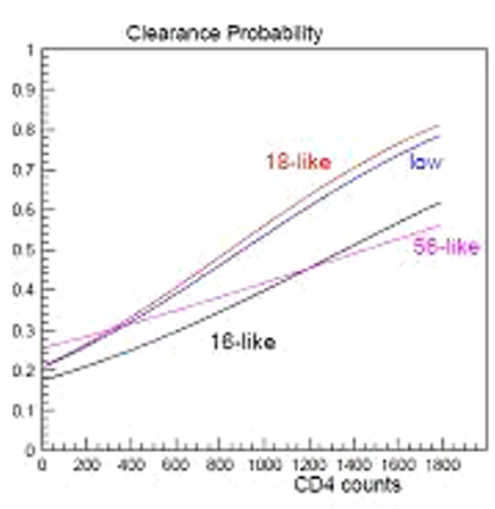

(A)

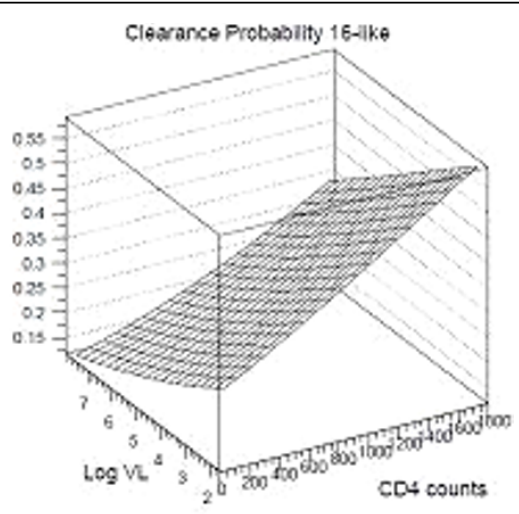

(B)

Figure 1 HPV infection clearance probability vs. (1A) CD4 counts and (1B) combination of CD4 and logarithm of HIV viral load (log(VL)).

*Correspondence: yk27@duke.edu

'Duke Comprehensive Cancer Center, Duke University, Durham, NC, USA

Full list of author information is available at the end of the article 
Health (REACH) cohort. At enrollment and every 6 months thereafter, cervical lavage samples were tested for HPV using MY09/MY11/HMB01-based PCR and $30 \mathrm{HPV}$ type-specific probes. HIV-related clinical data and risk factors were recorded every 3 months. For analytic purposes, HPV types were categorized according to phylogenetic patterns into (1) 16/16-like, (2) 18/18-like, (3) other high risk (56/56-like), and (4) low risk. HPV clearance was defined by the absence of type-specific infection for two subsequent visits after infection. Maximum likelihood estimates based on the logistic-type model were developed for 3-month reconstructed probabilities of HPV clearance/persistent with $\mathrm{CD} 4, \mathrm{VL}$, and HAART as the main predictors at the moment of examination.

\section{Results}

Figure 1A presents the clearance probability for HIVpositive patients depending on CD4 for HPV16/16-like, HPV18/18-like, HPV56/56-like, and low-risk HPV. HPV16/16-like infection has the lowest chance to be cleared by host at low CD4 levels. The probability of 3 -month clearance was less than $20 \%$ for patients with CD4 $<200$, but increased gradually with CD4 increase but overall was slower than for HPV18/18-like, other high-risk, and low-risk HPV. Additionally, the 3-D plot in Figure $1 \mathrm{~B}$ describes $\mathrm{CD} 4$ and $\log (\mathrm{VL})$ as predictors of probability of HPV16/16-like clearance: the lowest CD4 levels together with the highest VL were significant predictors for HPV persistence. The multiplicative effect of HAART showed tendency to decrease on HPV16/16-like clearance probability with increasing CD4 levels.

\section{Conclusion}

This approach could extend opportunities to understand the associations between $\mathrm{CD} 4, \mathrm{VL}$, and HAART to develop the comprehensive approach to individualized prediction of HPV infection persistence/clearance in HIV-positive patients.

\section{Acknowledgements}

This article has been published as part of Infectious Agents and Cancer Volume 5 Supplement 1, 2010: Proceedings of the $12^{\text {th }}$ International Conference on Malignancies in AIDS and Other Acquired Immunodeficiencies (ICMAOI). The full contents of the supplement are available online at http://www.biomedcentral.com/1750-9378/5?issue=S1.

\section{Author details}

${ }^{1}$ Duke Comprehensive Cancer Center, Duke University, Durham, NC, USA.

2Department of Epidemiology, University of Alabama at Birmingham, Birmingham, AL, USA. ${ }^{3}$ Center for Population Health and Aging, Duke University, Durham, NC, USA

Published: 11 October 2010
doi:10.1186/1750-9378-5-S1-A76

Cite this article as: Kravchenko et al:: The approach to individualized prediction of human papillomavirus (HPV) infection persistence/ clearance in HIV-1-positive adolescent girls based on dynamics of CD4+ counts, viral load, and HAART. Infectious Agents and Cancer 2010 5(Suppl 1):A76.

\section{Submit your next manuscript to BioMed Central} and take full advantage of:

- Convenient online submission

- Thorough peer review

- No space constraints or color figure charges

- Immediate publication on acceptance

- Inclusion in PubMed, CAS, Scopus and Google Scholar

- Research which is freely available for redistribution

Submit your manuscript at www.biomedcentral.com/submit 